\title{
ORIGINS OF THE INHIBITING EFFECTS OF NASAL CPAP ON NON- NUTRITIVE SWALLOWING IN NEWBORN LAMBS
}

\author{
Nathalie Samson ${ }^{\dagger}$, Bianca Roy $^{\dagger}$, Alain Ouimet ${ }^{\top}$, François Moreau-Bussière ${ }^{\dagger}$, \\ Dominique Dorion* ${ }^{\dagger}$, Jean-Paul Praud* ${ }^{\dagger}$
}

Équipe de recherche périnatale sur les ovins. †Departments of Pediatrics and Physiology, "Department of Surgery, *ENT Division, Université de Sherbrooke, Sherbrooke, QC, Canada J1H 5N4

Short title: CPAP and non-nutritive swallowing

Keywords: CPAP; non-nutritive swallowing; bronchopulmonary receptors

5949 words

Address for correspondence and proofs:

Jean-Paul Praud MD PhD

Departments of Pediatrics and Physiology

Université de Sherbrooke

J1H 5N4, QC Canada
Tel: (819) 346-1110, ext 14851

Fax: (819) 564-5215

email: Jean-Paul.Praud@USherbrooke.ca 


\section{Abstract}

The present study was aimed at investigating the principal reflex mechanism by which non-nutritive swallowing (NNS) is inhibited by application of a nasal CPAP 6 $\mathrm{cm} \mathrm{H}_{2} \mathrm{O}$ during quiet sleep (QS) in newborn lambs. Eighteen full-term lambs were chronically instrumented and evenly distributed into 3 separate groups to sort out whether reflex activity originates from the upper or lower airway receptors. Six lambs were tracheotomized, six other lambs underwent a 2-step bilateral intrathoracic vagotomy while the remaining 6 lambs underwent chronic laryngo-tracheal separation (isolated upper airway group). Forty-eight hours after surgery, each nonsedated lamb underwent polysomnographic recordings on 3 consecutive days. States of alertness, NNS and respiratory movements were recorded. Results demonstrate that a CPAP of $6 \mathrm{~cm} \mathrm{H}_{2} \mathrm{O}$ inhibited NNS during QS while administered directly on the lower airways. This NNS inhibition was prevented by eliminating the vagal afferent messages originating from the bronchopulmonary receptors. However, application of CPAP on the upper airways only also inhibited NNS during QS. Finally, the application of a CPAP $6 \mathrm{~cm} \mathrm{H}_{2} \mathrm{O}$ had no systematic effect on NNS-breathing coordination. In conclusion, our results suggest that the inhibiting effect of nasal CPAP $6 \mathrm{~cm} \mathrm{H}_{2} \mathrm{O}$ on NNS is mainly mediated by bronchopulmonary receptors with some participation however of upper airway receptors. Our demonstration that spontaneous, non-nutritive swallowing can be modulated by bronchopulmonary receptor activity further illustrates the physiological interactions between upper and lower airways. 


\section{Introduction}

Nasal continuous positive airway pressure (CPAP) has been widely used in newborns for a number of years as treatment for mild respiratory distress syndrome, apnoeas of prematurity and as a bridge between endotracheal tube ventilation and spontaneous ventilation (Ersch et al, 2007, Greenough; Prendergast, 2007, Miksch et al, 2008). However, laryngeal functions, such as non-nutritive swallowing (NNS) which fulfils the important task of clearing upper airways from secretions and liquids refluxed from the stomach, have not been specifically assessed in newborns during nasal CPAP, aside from one study whereby nasal CPAP was shown to increase laryngeal opening (Gaon et al, 1999). We recently reported that a nasal CPAP of 6 $\mathrm{cm} \mathrm{H}_{2} \mathrm{O}$ inhibits spontaneous NNS in newborn lambs during quiet sleep (QS) (Samson et al, 2005). While this inhibiting effect of nasal CPAP has been previously reported for water-induced swallowing in conscious adult humans (Nishino et al, 1989), the precise mechanism by which swallowing is inhibited by nasal CPAP remains unclear. Data from the literature either suggest an implication of the positive pressure receptors of the upper airways or the slow-adapting bronchopulmonary receptors of the lower airways. Indeed, a recent study has shown that direct application of continuous or intermittent positive pressure on isolated larynx of piglets can modulate laryngeal muscle activity (Stella; England, 2001), thus suggesting an

implication of positive pressure receptors of the upper airways. Alternatively, continuous lung inflation induced by application of continuous negative extra thoracic pressure in awake adult humans was also shown to significantly inhibit watertriggered swallowing activity, suggesting an implication of the slow-adapting bronchopulmonary receptors (Kijima et al, 2000). This latter hypothesis was further 
supported by the observation that voluntary hyperpnoea (hypocapnic or normocapnic) inhibits water-induced swallowing in awake adult humans (Yamamoto; Nishino, 2002). Therefore, the main aim of this study was to sort out whether the inhibitory effect of nasal CPAP on spontaneous NNS is mediated by stimulation of bronchopulmonary receptors and/or receptors located in the upper airways. 


\section{Materials and methods}

\section{Ethical approval}

All study protocols were approved by the ethics committee of the Université de Sherbrooke for animal care and experimentation.

\section{$\underline{\text { Animals }}$}

A total of eighteen lambs (three groups of 6 lambs) were included in the study. All animals harvested came from our usual local provider's farm.

\section{Common surgical preparation}

Aseptic surgery was performed under general anaesthesia ( $2 \%$ isoflurane, $30 \% \mathrm{~N}_{2} \mathrm{O}$, $68 \% \mathrm{O}_{2}$ ). Anaesthesia was preceded by an intramuscular injection of ketamine (10 $\mathrm{mg} / \mathrm{kg})$, atropine sulfate $(0.1 \mathrm{mg} / \mathrm{kg})$ and an intra-venous bolus $(10 \mathrm{ml} / \mathrm{kg})$ of Ringer lactate solution. Antibiotics $(5 \mathrm{mg} / \mathrm{kg}$ gentamicin and $0.05 \mathrm{ml} / \mathrm{kg}$ duplocilline) were administered intramuscularly prior to surgery and daily thereafter until the end of the experiments. One dose of ketoprofen ( $3 \mathrm{mg} / \mathrm{kg}$ intramuscularly) was systematically given immediately after induction of anaesthesia for analgesia and repeated if needed on the first postoperative day, $12 \mathrm{~h}$ after the first dose. Bipolar gold plated stainless steel barbed broach (3mm length) electrodes were inserted into both thyroarytenoid muscles (TA) through the lateral aspect of the thyroid cartilage for electrical activity (EMG) recording. A bipolar electrode, custom-manufactured from two stainless steel Michel coetaneous staples $(11 \mathrm{~mm}$ length, $2 \mathrm{~mm}$ width; CDMV, StHyacinthe, QC, Canada), was inserted $5 \mathrm{~cm}$ distal to the oesophageal inlet to record oesophageal muscle EMG. Two right-angled, platinum needle-electrodes (E7-12, Grass Instruments Company, Quincy, MA) were inserted into the parietal cortex 
directly through the skull, at the level of the lambda suture, $1 \mathrm{~cm}$ from midline, for electroencephalogram (EEG) recording. One platinum needle-electrode (E2-12, Grass Instruments Company) was also inserted under the scalp as a ground. Leads from each electrode were subcutaneously tunnelled to exit on the back of the animals. On the experimental day, just before recordings, two platinum needle electrodes (F-E2, Grass Instrument) were inserted subcutaneously into the outer lower region and the upper region of the right eye socket for electrooculogram (EOG) recording and secured with biological glue. Euthanasia was performed by an intravenous injection of $100 \mathrm{mg} / \mathrm{kg}$ of pentobarbital. Correct electrode positioning was systematically verified at autopsy.

\section{Specific surgical preparation}

Tracheotomized group. A tracheostomy was first performed between the fifth and sixth tracheal rings in the six lambs included in this group. An external tracheal tube was them sewn and glued around the tracheostomy, leaving the tracheal lumen free of any instrumentation, as previously described (Lemaire et al, 1999).

Bivagotomy group. A 2-step, bilateral, intrathoracic vagotomy using video assisted (Tele Pack control unit; no 20043120-020) thoracic surgery was performed in the six lambs included in this group. While lambs were in the ventral position and after cessation of $\mathrm{NO}_{2}$ use, a 5-mm trocar was inserted through the right sixth intercostal space in the posterior axillary line. A 5-mm rigid endoscope (Hopkins II, Karl Storz Endoscopy Canada, Mississauga, ON) was introduced through the trocar into the pleural cavity. A right pneumothorax was induced by insufflations of $\mathrm{CO}_{2}$ (3 to $6 \mathrm{~cm}$ $\mathrm{H}_{2} \mathrm{O}$ ) to visualize the thoracic portion of the vagus nerve. Further 2-mm surgical instruments (no 30340 FL, 30310 DBS, Karl Storz, Germany) were inserted without 
trocars in the right third intercostal space. The right vagus nerve was then dissected and isolated. After dissection, the central bared portion of an enamelled chrome wire electrode (0.12 mm diameter; Leico Industries Inc, New-York, USA) was positioned around the right vagus nerve, immediately caudal to the origin of the laryngeal recurrent nerve. The two free ends of the enamelled chrome wire were slid into a polyethylene tubing of 0.1-cm-OD (no 427411, Intramedic, Becton Dickinson, New Jersey, USA) and ultimately exited the pleural cavity through the third intercostal space. The outer ends of the electrode were anchored to the skin with Dexon suture. Finally, the $\mathrm{CO}_{2}$ pneumothorax was drained and the intercostal openings sutured. Once completed, a similar procedure was subsequently performed on the left side. Throughout the procedures, arterial blood gases and hemodynamic parameters were monitored and corrected if needed, by modifying ventilatory parameters, saline infusion and/or epinephrine injection.

Isolated upper airway group. The six lambs included in this group underwent a laryngo-tracheal separation to isolate the upper airways. The caudal end of the larynx was sewn and glued to a $2 \mathrm{~cm}$-long Dacron aortic prosthesis tube, whose extremity was sutured to a neck stoma. The rostral end of the trachea was sewn closed and an external tracheal tube was installed around a tracheostomy performed between the fifth and sixth tracheal ring, as described above for lambs of the tracheotomized group.

\section{$\underline{\text { Recording equipment }}$}

In order to obtain data from prolonged recordings (with periods of wakefulness and sleep) in lambs under the least possible restraining conditions, we used our customdesigned radio telemetry system, composed of eight channels for nasal flow, ECG, 
EOG, EEG and EMG recordings (Letourneau et al, 1999). Signals from the transmitter, located in a pocket of the animal vest, were fed from the receiver to the acquisition system. The raw EMG signals were rectified, integrated and averaged (moving time average of $100 \mathrm{~ms}$ ). Thoracic and abdominal movements and qualitative variations of lung volume were monitored in all lambs with the use of respiratory inductance plethysmography (Respitrace, NIMS, Miami Beach, FL). A custom-manufactured nasal mask was also installed on the muzzle of each lamb during nasal ventilation periods, in such a manner that animals were able to open their mouth at will (Samson et al, 2005). During tracheal ventilation periods (tracheotomized group only), a cuffed endotracheal tube was inserted through the external tracheotomy tube installed during surgery. Nasal and tracheal CPAP were administered by using a Neopuff infant resuscitator mechanical ventilator (Fisher \& Paykel Healthcare, Auckland, New-Zealand) with heated $\left(33^{\circ} \mathrm{C}\right)$, humidified air. Polysomnographic signals were recorded on a personal PC computer using a computerized acquisition device (MP100, Biopac Systems, Santa Barbara, CA) and software (Acknowledge 3.7.3, Biopac Systems). In addition, lambs were continuously monitored by an observer constantly present in the laboratory to note all events occurring during recordings. Collected data were stored on compact disk for further analysis.

\section{Design of the study}

On arrival in our animal quarters, all lambs were housed with their mother, with the exception of lambs in the isolated upper airway group, because of specific care related to permanent tracheostomy breathing. Lambs from that group were placed in a Plexiglas chamber $\left(1.2 \mathrm{~m}^{3}\right.$, in agreement with recommendations by the Canadian 
Council for Animal Care for sheep housing), through which water-saturated air was continuously flowed (10 L/min) using an Allegiance Airlife ${ }^{\mathrm{TM}}$ Nebulizer no 5207 and a home humidifier. Tracheal secretions were systematically suctioned at least three times a day, according to American Thoracic Society recommendations (Sherman et al, 2000). Lambs from that group were also fed ad libitum three times a day with ewe's milk at 8:00 AM, 12:00 PM and 4:00 PM.

All lambs were studied without sedation beginning 48 hours after surgery, thus on the fourth day of life, between 6:00 AM and 12:00 PM. Polysomnographic recordings were performed for 4 to 6 hours on 3 consecutive days, at post-chirurgical days 2, 3 and 4 for the tracheotomized and isolated upper airways groups, and on postchirurgical days 3,4 and 5 for the bivagotomy group. Lights were turned off throughout the recordings. Each lamb was studied without sedation, while placed in a Plexiglas chamber $(1.2 \times 1.2 \times 1 \mathrm{~m})$, where it could move as freely as possible (connected to the ventilator) and sleep in the position it felt the most comfortable in, which was variable from one lamb to another.

\section{BRONCHOPULMONARY RECEPTOR STUDIES}

Tracheotomized group. Three different experimental conditions (one per day) were tested in a random order: 1) a control recording during which the lamb breathed through its nasal mask, without CPAP, and with the tracheostomy tube closed (no CPAP); 2) a recording during administration of a $6 \mathrm{cmH}_{2} \mathrm{O}$ CPAP through the nasal mask with the tracheostomy tube closed (nasal CPAP, nCPAP); 3) a recording during administration of a $6 \mathrm{cmH}_{2} \mathrm{O}$ CPAP through a cuffed tracheostomy tube (tracheal CPAP, tCPAP). 
Bivagotomy group. Three different experimental conditions were tested but only the first two conditions could be randomized: 1) a control recording during which the lamb breathed through its nasal mask, without CPAP and with intact vagi (no CPAP); 2) a recording during administration of a $6 \mathrm{cmH}_{2} \mathrm{O} C P A P$ through the nasal mask and with intact vagi (nasal CPAP pre-vagotomy, pre-vago). The third experimental condition was carried out on the last experimental day. A $6 \mathrm{cmH}_{2} \mathrm{O}$ CPAP was administered through the nasal mask after thoracic bivagotomy (nasal CPAP post-vagotomy, postvago). Thoracic bivagotomy was performed by attaching the free ends of each metal wire electrode positioned around the vagus nerve to an electrocauter (model 770 , set at cutting power 3/11, Electrosectilis, Britcher, CA). Traction was then applied to the wire electrode during electrocautery, thus sectioning the vagus nerve. The procedure was completed in less than $5 \mathrm{sec}$ and resulted in minimal discomfort (no visible reaction or a short startle at most) for the lamb. The procedure was repeated on the second side right after completion of the first vagotomy. Complete, bilateral vagotomy was always verified at autopsy.

\section{ISOLATED UPPER AIRWAY RECEPTOR STUDY}

Isolated upper airway group. Three different experimental conditions were tested in random order: 1) a control recording during which the lamb breathed through the tracheostomy tube with the presence of the nasal mask on, but without CPAP (no CPAP); 2) a recording during administration of a $6 \mathrm{cmH}_{2} \mathrm{O}$ CPAP through the nasal mask, directly on the upper airways only, while the lamb breathed normally through the tracheostomy tube (CPAP 6 on the upper airways (UA), CPAP 6 UA); 3) a recording during administration of a $6 \mathrm{cmH}_{2} \mathrm{O}$ CPAP through the tracheostomy tube, directly on the lower airways (CPAP 6 on the lower airways (LA), CPAP 6 LA). 


\section{Data analysis}

States of alertness. All signals were carefully observed and analyzed throughout the recordings in relation to the states of alertness. However, since we had previously demonstrated that the inhibiting effect of CPAP administration was significant in quiet sleep (QS) specifically (Samson et al, 2005), only the data recorded during QS were considered for present results. Standard electrophysiological and behavioural criteria were used to define wakefulness (W), quiet sleep (QS), active sleep (AS), and arousal, as previously described (Renolleau et al, 1999).

Non-nutritive swallowing activity. NNS activity was recognized by a brief, highamplitude TA EMG burst, as previously validated (Reix et al, 2003). Many TA EMG bursts were followed by a high amplitude oesophageal EMG burst (propagated NNS). NNS were defined depending on the respiratory phase preceding and following NNS. Four types of NNS were described: e-type NNS (preceded and followed by expiration), ei-type NNS (at the transition from expiration to inspiration), ie-type NNS (at the transition from inspiration to expiration) and $i$-type NNS (preceded and followed by inspiration) as previously described (Reix et al, 2003). NNS activity was then characterized either as an isolated NNS or a burst of NNS, which was defined for the purpose of this study as at least two NNS occurring within a period of $4 \mathrm{~s}$ (Samson et al, 2005). The first analysis consisted in calculation of NNS frequency (number of NNS per hour) for isolated NNS, bursts of NNS, and total NNS (isolated + bursts of NNS) for QS only, for each group and under each experimental condition. Then, the sum signal of the respiratory inductance plethysmography was used to recognize the phase of the respiratory cycle disrupted by isolated NNS. NNS frequency was then calculated for each type of isolated NNS during QS, for each group and under each experimental condition. 
Statistical analysis. Statistical analyses were performed through the use of the SAS software. For quantitative variables, data are expressed as mean and standard deviation (SD). Results on NNS frequency were first averaged for each lamb, and then averaged for the 6 lambs as a whole for each group. Normality was tested using the Shapiro-Wilks test (normal distribution if $p>0.05$ ). The effects of each experimental condition were then tested for each group by generalized linear models with repeated measures (GENMOD procedure) consisting in a normal regression model (total, isolated or burst of NNS) or a Poisson regression model (NNS-breathing coordination). One-way ANOVAs were also used to test statistical differences between our animal models. A value of $p<0.05$ was considered as statistically significant. 


\section{Results}

\section{General characteristics}

General characteristics relative to weight on the day of surgery, arterial blood gases during the different experimental conditions and states of alertness (total time spent in QS) are given for all lambs in Table 1. A total of six lambs were included in each group with the exception of the ICPAP condition in the tracheotomized group and the CPAP 6 LA condition in the isolated upper airway group, in which only five lambs were analyzed.

No statistical differences were observed $(P=0.6)$ when comparing NNS frequency during no CPAP conditions for all three experimental groups [tracheotomized (45 \pm $\left.17 \mathrm{~h}^{-1}\right)$, bivagotomy $\left(38 \pm 10 \mathrm{~h}^{-1}\right)$ and isolated upper airway (43 $\left.\pm 13 \mathrm{~h}^{-1}\right)$ group]. These results were similar to our previous results (Samson et al, 2005) obtained under the same conditions but in lambs with intact airways $\left(36 \pm 14 \mathrm{~h}^{-1}\right)$ (Fig.1).

\section{Effect of positive airway pressure on NNS frequency}

The effects of positive airway pressure on NNS frequency are reported in table 2 and fig. 2, for each group and for each experimental condition.

\section{BRONCHOPULMONARY RECEPTOR STUDIES}

Tracheotomized group. Compared to control conditions (no CPAP), both nasal (nCPAP) and tracheal (tCPAP) CPAP $6 \mathrm{~cm} \mathrm{H}_{2} \mathrm{O}$ inhibited total $(\mathrm{P} \leq 0.0001)$ and isolated $(P \leq 0.0001)$ NNS frequency during QS. However, only nasal CPAP $6 \mathrm{~cm}$ $\mathrm{H}_{2} \mathrm{O}(\mathrm{P}=0.001)$ inhibited bursts of NNS frequency during $\mathrm{QS}$.

Bivagotomy group. Compared to control conditions (no CPAP), application of nasal CPAP $6 \mathrm{~cm} \mathrm{H} \mathrm{H}_{2} \mathrm{O}$ with intact vagus nerves (pre-vago) inhibited total $(P<0.0001)$, isolated $(P<0.0001)$ and bursts $(P=0.01)$ of NNS during QS. Oppositely, NNS 
inhibition during QS was prevented after bilateral vagotomy (post-vago) $(P \geq 0.4$ vs. control).

\section{ISOLATED UPPER AIRWAY RECEPTOR STUDY}

Isolated upper airway group. Compared to control conditions (no CPAP), application of CPAP $6 \mathrm{~cm} \mathrm{H}_{2} \mathrm{O}$ on either the upper (CPAP $6 \mathrm{UA}$ ) or the lower (CPAP 6 LA) airways inhibited total $(P \leq 0.0007)$ and isolated $(P \leq 0.01)$ NNS frequency during QS. On the other hand, only the application of CPAP $6 \mathrm{~cm} \mathrm{H}_{2} \mathrm{O}$ on the upper airways $(P=0.04)$ inhibited bursts of NNS frequency during QS.

IN SUMmARY, application of CPAP of $6 \mathrm{~cm} \mathrm{H}_{2} \mathrm{O}$ inhibited total and isolated NNS frequency when administered directly on the lower airways for both the tracheotomized (tCPAP) and isolated upper airway (CPAP 6 LA) groups. This NNS inhibition was prevented by eliminating vagal afferent messages originating from the bronchopulmonary receptors (post-vago experimental condition). In addition, application of CPAP on the upper airways only (CPAP 6 UA) inhibited total, isolated and bursts of NNS frequency during QS.

\section{NNS-breathing coordination}

The effects of $6 \mathrm{~cm} \mathrm{H} \mathrm{H}_{2} \mathrm{O}$ CPAP on NNS-breathing coordination are reported in table 3 and fig. 3. Overall, NNS-breathing coordination was similar for all experimental conditions. Indeed, $i$-type NNS were the most frequent, as opposed to e-type NNS which were the least common. Furthermore, ei-type NNS were slightly more frequent than ie-type NNS in almost all experimental conditions, with the exception of the prevago condition of the bivagotomy group and the no CPAP condition of the isolated upper airway group. 


\section{BRONCHOPULMONARY RECEPTOR STUDIES}

Tracheotomized group. Compared to control conditions (no CPAP), both tCPAP 6 $(P=0.009)$ and nCPAP $6(P=0.003)$ slightly decreased $i$-type NNS. Moreover, nCPAP 6 also decreased ei-type NNS $(P=0.009)$. An increase in e-type NNS with tCPAP6 appeared as the sole exception $(P=0.008)$.

Bivagotomy group. Compared to control conditions (no CPAP), application of nasal CPAP $6 \mathrm{~cm} \mathrm{H}_{2} \mathrm{O}$ with intact vagus nerves (pre-vago) decreased both ei-type NNS ( $P$ $=0.0002)$ and e-type NNS $(P<0.0001)$. In contrast, application of nasal CPAP $6 \mathrm{~cm}$ $\mathrm{H}_{2} \mathrm{O}$ after bilateral vagotomy (post-vago) did not alter NNS-breathing coordination.

\section{ISOLATED UPPER AIRWAY RECEPTOR STUDY}

Isolated upper airway group. Compared to control conditions (no CPAP), application of CPAP $6 \mathrm{~cm} \mathrm{H}_{2} \mathrm{O}$ on the lower airways (CPAP 6 LA) decreased both ietype NNS $(P<0.0001)$ and e-type NNS $(P=0.002)$. Application of CPAP $6 \mathrm{~cm} \mathrm{H} \mathrm{H}_{2} \mathrm{O}$ on the upper airways (CPAP $6 \cup A)$ also decreased $i$-type NNS $(P=0.02)$.

OverALL, application of CPAP $6 \mathrm{~cm} \mathrm{H}_{2} \mathrm{O}$ in the present studies had no systematic effect on NNS-breathing coordination. The only effect observed was a slight decrease in variable types of NNS, specific for each group, with the exception of an increase in e-type NNS with tCPAP6 (tracheotomized group). 


\section{Discussion}

\section{Statement of principal findings}

The present study provides new insight on reflex mechanisms, which are involved in the inhibiting effects of nasal CPAP on spontaneous NNS during QS in the neonatal period. Our results demonstrate that a CPAP of $6 \mathrm{~cm} \mathrm{H}_{2} \mathrm{O}$ inhibits NNS during QS when administered directly on the lower (sub glottal) airways. Furthermore, this NNS inhibition is prevented when the vast majority of vagal afferent messages, originating from bronchopulmonary receptors, are eliminated by bilateral vagotomy. However, our results also reveal that the application of a CPAP of $6 \mathrm{~cm} \mathrm{H} \mathrm{H}_{2} \mathrm{O}$ on the upper airways only slightly inhibits NNS during QS on its own. Finally, the present study reveals that application of CPAP does not alter NNS-breathing coordination in any of our animal models, all of which are uniquely designed using sophisticated surgical techniques.

\section{Effect of positive airway pressure on NNS frequency}

Application of nasal CPAP has been previously shown to inhibit water-induced swallowing in conscious adult humans (Nishino et al, 1989) and spontaneous NNS in newborn lambs during QS (Samson et al, 2005). However, the precise reflex mechanism(s) by which swallowing is inhibited by nasal CPAP remains unclear. Data from the literature either suggest an implication of upper airways receptors or bronchopulmonary receptors.

\section{BRONCHOPULMONARY RECEPTOR STUDIES}

Three types of afferent bronchopulmonary receptors are traditionally described, including the slow adapting stretch receptors, the rapidly adapting stretch receptors or "irritant" receptors and the bronchopulmonary C-fibre endings (Widdicombe, 2001). 
Since administration of CPAP is associated with lung inflation at a constant transmural pressure, rapidly adapting receptors and bronchopulmonary C-fibres are not stimulated by CPAP (Bailey; Fregosi, 2006). Thus, application of nasal CPAP could particularly inhibit NNS by stimulation of slow-adapting bronchopulmonary receptors by a vagally mediated lung reflex. In support of this hypothesis, continuous lung inflation brought about by application of continuous negative extra thoracic pressure in awake adult humans was observed to significantly inhibit water-triggered swallows (Kijima et al, 2000). In addition, voluntary hyperpnoea (hypocapnic or normocapnic) was shown to inhibit water-induced swallowing in awake, adult humans (Yamamoto; Nishino, 2002). Moreover, our present results in newborn lambs whereby a tracheal CPAP of $6 \mathrm{~cm} \mathrm{H}_{2} \mathrm{O}$ inhibits NNS in a manner similar to that by nasal CPAP suggest the involvement of bronchopulmonary receptors in this inhibiting effect. This hypothesis is further confirmed in our bivagotomy group in which NNS inhibition by nasal CPAP was prevented after bilateral vagotomy. In brief, the present data strongly suggest that the inhibiting effect of nasal CPAP on NNS during QS in the newborn lamb is mediated by a reflex mechanism originating from the bronchopulmonary receptors, most likely the slow-adapting pulmonary stretch receptors.

\section{ISOLATED UPPER AIRWAY RECEPTORS STUDY}

Theoretically, inhibition of NNS could be elicited by stimulation of upper airway receptors. At least five types of afferent receptors have been described in the upper airways. They include pressure, drive, cold (flow), irritant and C-fibre receptors, all of which are particularly numerous in the nasal and laryngeal regions (Sant'Ambrogio et al, 1995). The pressure receptors, whose activity is modulated by application of negative or positive pressure in the upper airways, account for the vast majority of 
receptors of the nasal and laryngeal region (Sant'Ambrogio et al, 1995). Since the air administered in experiments herein was heated at body temperature and at a constant pressure, the inhibiting effect observed with application of CPAP on isolated upper airways is most probably mediated by stimulation of positive pressure receptors. Interestingly, a recent study demonstrated that direct application of CPAP on the isolated larynx also modulates laryngeal muscle activity in piglets (Stella; England, 2001). However, the inhibiting action of CPAP derived from upper airway receptors in the present study appears weaker than that originating from bronchopulmonary receptors, since it was not observed in bilaterally vagotomized lambs.

Overall, our results strongly suggest that NNS inhibition by nasal CPAP is mainly mediated by stimulation of bronchopulmonary receptors, with some weaker participation of upper airway receptors.

\section{NNS-breathing coordination}

NNS breathing-coordination is crucial for minimizing the risk of aspiration or prolonged apnoeas, especially in vulnerable infants, such as preterm newborns. Results of the present study confirm our previous results that inspiratory NNS are more frequent than expiratory NNS in control conditions (no CPAP) in newborn lambs (Reix et al, 2003, Samson et al, 2005). These results also illustrate that, overall, the application of a $6 \mathrm{~cm} \mathrm{H}_{2} \mathrm{O}$ CPAP in newborn lambs has no systematic effect on NNS breathing-coordination in our three different animal models and experimental conditions. Of note, the absence of any alteration, after elimination of the majority of bronchopulmonary afferent messages by bilateral vagotomy, suggests that they are not important for NNS-breathing coordination. This further supports the view that 
NNS-breathing coordination appears to be hardwired at the central nervous system level from birth.

\section{$\underline{\text { Validation of our animal models }}$}

According to a recent review on the subject, there are still considerable gaps in our knowledge of the modulation of upper airway muscles by respiratory reflexes in general, and by bronchopulmonary afferents in particular (Bailey; Fregosi, 2006). With this in mind and in order to identify the reflex mechanisms responsible for the inhibiting effects of nasal CPAP on NNS, we specifically developed two unique animal models to study the effects of upper airway vs. bronchopulmonary receptors on the regulation of upper airway functions.

For our first model, we developed a chronically isolated upper airway lamb preparation with the help of an ENT surgeon (DD) with extensive experience in upper airway reconstruction. The relevance of this model for our physiological studies on swallowing is strongly suggested by clinical observation, which showed that bottlefeeding was identical to that in lambs with intact airways, and that there were no signs of upper airway hypersecretion. In addition, NNS frequency in baseline conditions (CPAP $0 \mathrm{cmH}_{2} \mathrm{O}$ ) was not significantly different from lambs in the other experimental groups of the present study, or from lambs having undergone no airway surgery from a previous study in our lab (Samson et al, 2005). Secondly, we developed an equally unique lamb model using a 2-step, intrathoracic bilateral vagotomy, with the help of a paediatric surgeon with an extensive expertise in videoassisted thoracic surgery (AO). This model offers several advantages over previously reported lamb models with bilateral vagotomy (Praud et al, 1992, Wong et al, 1998). On the one hand, the use of video-assisted thoracic surgery, though challenging in 
the neonatal period from both a surgical and anaesthesiological standpoint, allows for a much less aggressive intervention than when using a standard thoracotomy, which is advantageous from both a physiological and ethical standpoint. In addition, the 2step procedure is better tolerated by the lamb, allowing to wait for postoperative recovery during which the two vagal nerves still remain operational, and to use each lamb as its own control, thus decreasing the number of lambs needed. Again, the relevance of this unique bilateral vagotomy model was shown by the absence of observable swallowing abnormalities, both clinically during and between bottlefeeding and when computing NNS frequency in baseline conditions (CPAP 0 $\left.\mathrm{CmH}_{2} \mathrm{O}\right)$.

Hence, the development of these 2 unique lamb models constitutes a very important aspect of the present study. It paves the way for further studies exploring the origins of various upper airway functions in the neonatal period, including, e.g., studies on the laryngeal chemoreflexes (St-Hilaire et al, 2005) or during nasal ventilation (Moreau-Bussiere et al, 2007).

In conclusion, the present study illustrates for the first time that the inhibiting effect of nasal CPAP on NNS in newborn lambs during QS is especially mediated by stimulation of the bronchopulmonary receptors (most likely the slow-adapting stretch receptors), with some weaker participation of the upper airway receptors. The results also illustrate that, overall, the application of a $6 \mathrm{~cm} \mathrm{H} \mathrm{H}_{2} \mathrm{O}$ CPAP in newborn lambs has no systematic effect on NNS-breathing coordination, suggesting that NNSbreathing coordination is hardwired at the central nervous system level from birth. Finally, the present study has enabled the development of two unique and sophisticated animal models relevant for studying the modulation of upper airway muscles by bronchopulmonary afferents. 


\section{References}

Bailey EF, Fregosi RF. (2006). Modulation of upper airway muscle activities by bronchopulmonary afferents. J Appl Physiol 101, 609-17.

Ersch J, Roth-Kleiner M, Baeckert P, Bucher HU. (2007). Increasing incidence of respiratory distress in neonates. Acta Paediatr 96, 1577-81.

Gaon P, Lee S, Hannan S, Ingram D, Milner AD. (1999). Assessment of effect of nasal continuous positive pressure on laryngeal opening using fibre optic laryngoscopy. Arch Dis Child Fetal Neonatal Ed 80, F230-2.

Greenough A, Prendergast M. (2007). Difficult extubation in low birth weight infants. Arch Dis Child Fetal Neonatal Ed ; DOI: 10.1136/adc.2007.121335.

Kijima M, Isono S, Nishino T. (2000). Modulation of swallowing reflex by lung volume changes. Am J Respir Crit Care Med 162, 1855-8.

Lemaire D, Letourneau P, Dorion D, Praud JP. (1999). Complete glottic closure during central apnea in lambs. J Otolaryngol 28, 13-9.

Letourneau P, Dumont S, Kianicka I, Diaz V, Dorion D, Drolet R, et al. (1999). Radiotelemetry system for apnea study in lambs. Respir Physiol 116, 85-93.

Miksch RM, Armbrust S, Pahnke J, Fusch C. (2008). Outcome of very low birthweight infants after introducing a new standard regime with the early use of nasal CPAP. Eur J Pediatr ; DOI: 10.1007/s00431-007-0646-1. 
Moreau-Bussiere F, Samson N, St-Hilaire M, Reix P, Lafond JR, Nsegbe E, et al. (2007). Laryngeal response to nasal ventilation in nonsedated newborn lambs. J Appl Physiol 102, 2149-57.

Nishino T, Sugimori K, Kohchi A, Hiraga K. (1989). Nasal constant positive airway pressure inhibits the swallowing reflex. Am Rev Respir Dis 140, 1290-3.

Praud JP, Canet E, Bureau MA. (1992). Chemoreceptor and vagal influences on thyroarytenoid muscle activity in awake lambs during hypoxia. J Appl Physiol 72, 962-9.

Reix P, Fortier PH, Niyonsenga T, Arsenault J, Letourneau P, Praud JP. (2003). Nonnutritive swallowing and respiration coordination in full-term newborn lambs. Respir Physiol Neurobiol 134, 209-18.

Renolleau S, Letourneau P, Niyonsenga T, Praud JP, Gagne B. (1999). Thyroarytenoid muscle electrical activity during spontaneous apneas in preterm lambs. Am J Respir Crit Care Med 159, 1396-404.

Samson N, St-Hilaire M, Nsegbe E, Reix P, Moreau-Bussiere F, Praud JP. (2005). Effect of nasal continuous or intermittent positive airway pressure on nonnutritive swallowing in the newborn lamb. J Appl Physiol 99, 1636-42.

Sant'Ambrogio G, Tsubone H, Sant'Ambrogio FB. (1995). Sensory information from the upper airway: Role in the control of breathing. Respir Physiol 102, 1-16.

Sherman JM, Davis S, Albamonte-Petrick S, Chatburn RL, Fitton C, Green C, et al. (2000). Care of the child with a chronic tracheostomy. this official statement of the 
american thoracic society was adopted by the ATS board of directors, july 1999. Am J Respir Crit Care Med 161, 297-308.

Stella MH, England SJ. (2001). Laryngeal muscle response to phasic and tonic upper airway pressure and flow. J Appl Physiol 91, 905-11.

St-Hilaire M, Nsegbe E, Gagnon-Gervais K, Samson N, Moreau-Bussiere F, Fortier $\mathrm{PH}$, et al. (2005). Laryngeal chemoreflexes induced by acid, water, and saline in nonsedated newborn lambs during quiet sleep. J Appl Physio/ 98, 2197-203.

Widdicombe J. (2001). Airway receptors. Respir Physiol 125, 3-15.

Wong KA, Bano A, Rigaux A, Wang B, Bharadwaj B, Schurch S, et al. (1998). Pulmonary vagal innervation is required to establish adequate alveolar ventilation in the newborn lamb. J Appl Physiol 85, 849-59.

Yamamoto F, Nishino T. (2002). Phasic vagal influence on the rate and timing of reflex swallowing. Am J Respir Crit Care Med 165, 1400-3. 


\section{Acknowledgement}

The authors gratefully acknowledge Jean-Philippe Gagné for invaluable technical support, as well as Nathalie Carrier for expert assistance with the statistical analyses. Also, we would like to acknowledge the Storz company for the loan of the videothoracic surgery equipment.

\section{Grants}

Nathalie Samson is a recipient of a Canada doctoral research scholarship from the Canadian Institutes of Health Research (Bourse d'études supérieures du Canada). Jean-Paul Praud is a national scholar of the Fonds de recherche en santé du Québec. The research is supported by grants from the Canadian Institute for Health Research (MOP 15558) and the Foundation of Stars. Jean-Paul Praud is a member of the FRSQ-funded Centre de recherche clinique Étienne-Le Bel du CHUS. 
Table 1: General characteristics relative to animal weight, blood gases and states of alertness for each study

\begin{tabular}{|c|c|c|c|c|c|c|c|c|c|}
\hline Weight (kg) & \multicolumn{3}{|c|}{$3.7 \pm 0.8$ (range $2.8-4.7)$} & \multicolumn{3}{|c|}{$3.9 \pm 0.7$ (range $3.3-5.1)$} & \multicolumn{3}{|c|}{$3.5 \pm 0.6$ (range $2.8-4.5)$} \\
\hline $\begin{array}{c}\text { States of alertness } \\
\text { (time spent in QS) } \\
\text { (hour) }\end{array}$ & $\begin{array}{l}\text { No CPAP } \\
2.0 \pm 0.1\end{array}$ & $\begin{array}{l}\text { nCPAP } \\
2.3 \pm 0.2\end{array}$ & $\begin{array}{c}\text { tCPAP } \\
2.2 \pm 0.2\end{array}$ & $\begin{array}{l}\text { No CPAP } \\
2.0 \pm 0.2\end{array}$ & $\begin{array}{l}\text { Pre-vago } \\
1.9 \pm 0.2\end{array}$ & $\begin{array}{l}\text { Post-vago } \\
2.0 \pm 0.06\end{array}$ & $\begin{array}{l}\text { No CPAP } \\
2.0 \pm 0.2\end{array}$ & $\begin{array}{l}\text { CPAP6 UA } \\
2.0 \pm 0.1\end{array}$ & $\begin{array}{l}\text { CPAP6 LA } \\
1.9 \pm 0.1\end{array}$ \\
\hline $\mathrm{pH}$ & $7.47 \pm 0.03$ & $7.45 \pm 0.04$ & $7.46 \pm 0.01$ & $7.46 \pm 0.03$ & $7.46 \pm 0.03$ & $7.46 \pm 0.03$ & $7.46 \pm 0.04$ & $7.46 \pm 0.04$ & $7.46 \pm 0.04$ \\
\hline $\mathrm{PCO}_{2}$ & $38.2 \pm 2.9$ & $37.0 \pm 3.6$ & $38.8 \pm 3.8$ & $36.3 \pm 2.4$ & $36.1 \pm 2.4$ & $36.0 \pm 2.5$ & $36.7 \pm 4.4$ & $36.7 \pm 4.4$ & $36.4 \pm 4.3$ \\
\hline $\mathrm{PO}_{2}$ & $73.2 \pm 13.0$ & $86.6 \pm 11.3$ & $75.7 \pm 10.8$ & $71.8 \pm 8.6$ & $73.6 \pm 10.7$ & $74.0 \pm 10.3$ & $67.6 \pm 11.0$ & $67.6 \pm 11.0$ & $69.1 \pm 11.8$ \\
\hline
\end{tabular}

Values are expressed as mean \pm SD. No CPAP, lambs breathed through a nasal mask without CPAP; nCPAP, lambs breathed through a nasal mask during administration of $6 \mathrm{cmH}_{2} \mathrm{O}$ CPAP; tCPAP, lambs breathed through a tracheostomy tube during administration of $6 \mathrm{cmH}_{2} \mathrm{O}$ CPAP; Pre-vago, lambs breathed through a nasal mask during administration of $6 \mathrm{cmH}_{2} \mathrm{O} C P A P$ before bi-vagotomy; Post-vago, lambs breathed through a nasal mask during administration of $6 \mathrm{cmH}_{2} \mathrm{O}$ CPAP after bi-lateral vagotomy; CPAP 6 UA, lambs breathed through a tracheostomy tube during administration of $6 \mathrm{cmH}_{2} \mathrm{O}$ CPAP on the upper airways only; CPAP 6 LA, lambs breathed through a tracheostomy tube during administration of $6 \mathrm{cmH}_{2} \mathrm{O}$ CPAP on the lower airways only. 
Table 2: Frequency of total NNS, isolated NNS and NNS bursts for all three studies during quiet sleep

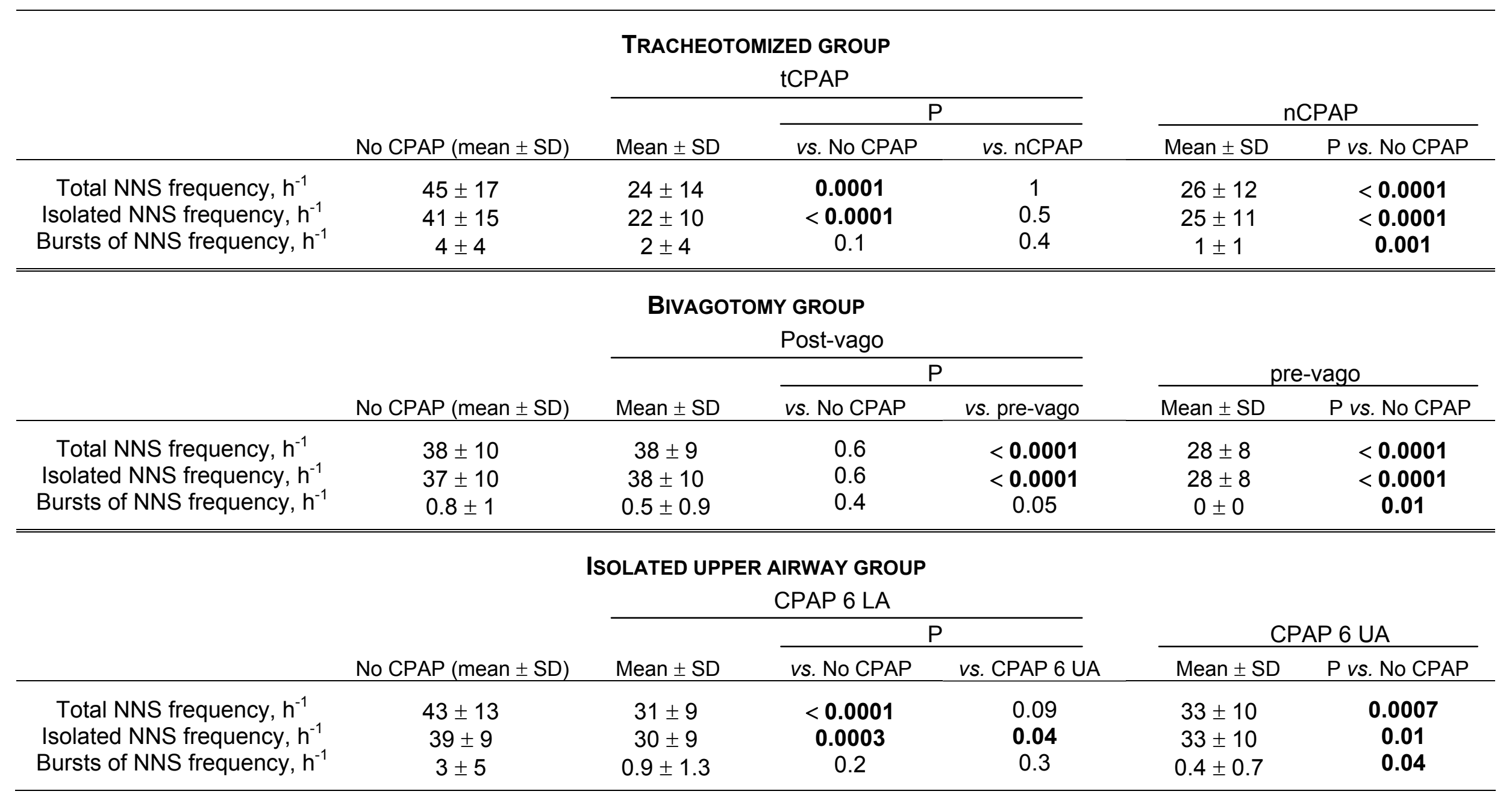

$\mathrm{n}=6$ for each study with the exception of the tCPAP condition in the tracheotomized group and the CPAP 6 LA condition in the isolated upper airway group, in which $n=5$. NNS, non-nutritive swallowing. $P$ values in bold indicate statistically significant differences. 
Table 3: Coordination between NNS and phases of the respiratory cycles

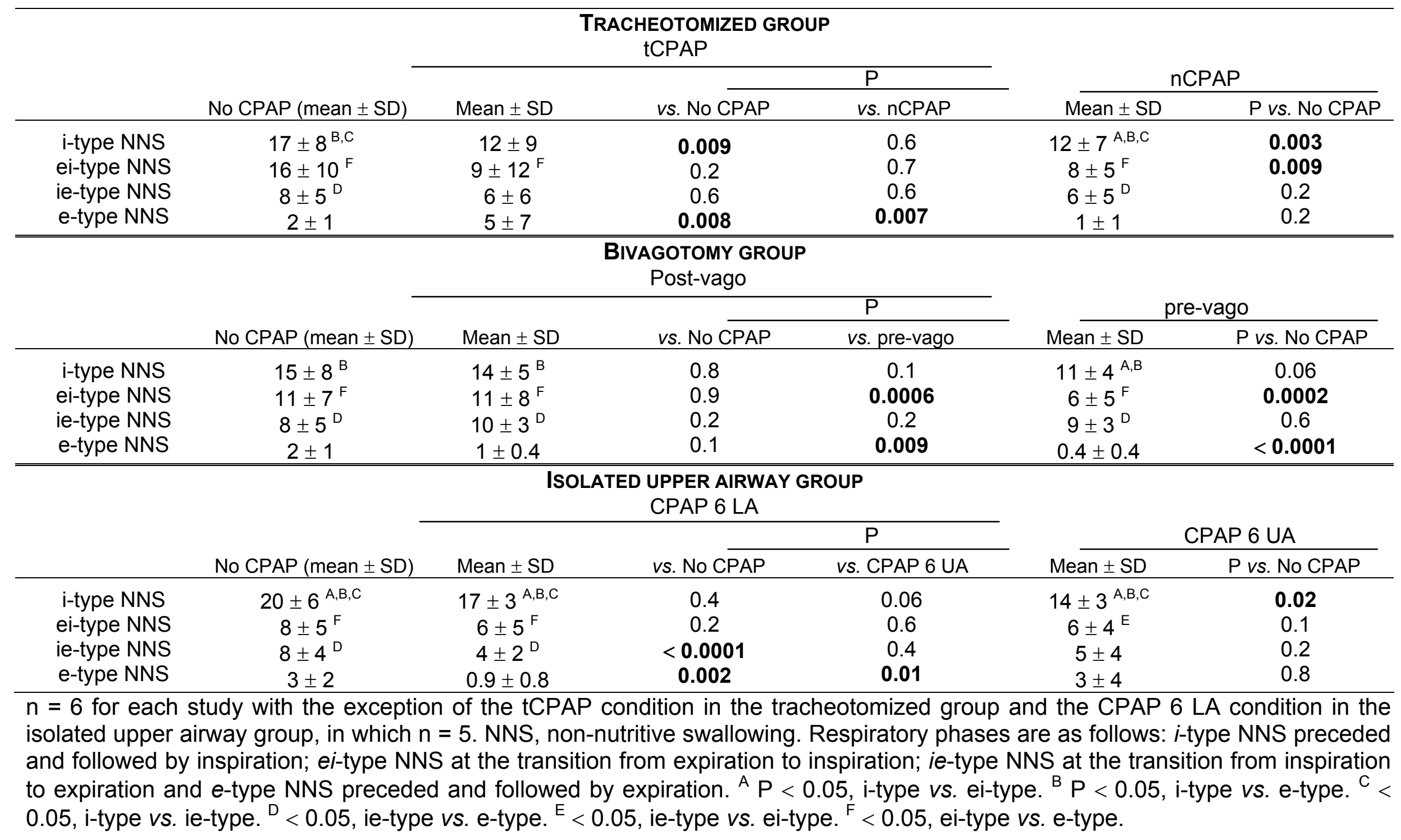




\section{Figures}

\section{Figure 1:}

Comparison of NNS frequency during No CPAP conditions for all three experimental groups with previous results in lambs with intact airways

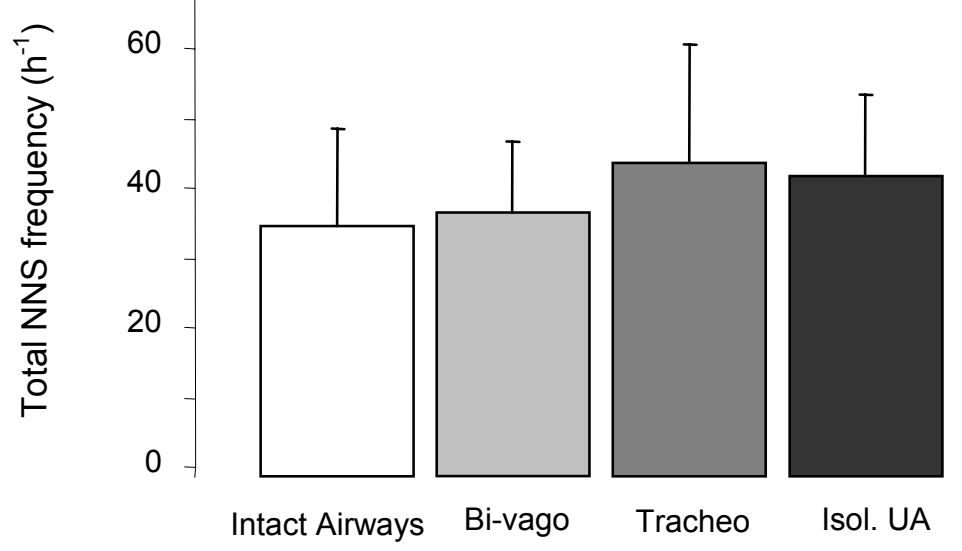


Figure 2:

Effect of continuous positive airway pressure on NNS frequency

Tracheotomized group Bivagotomy group
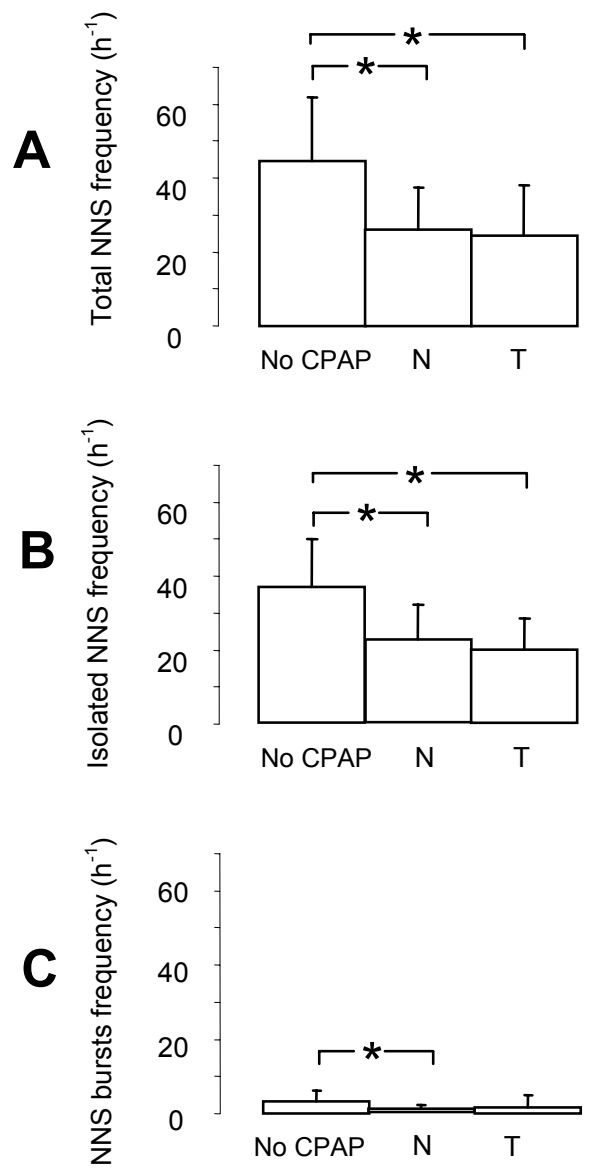
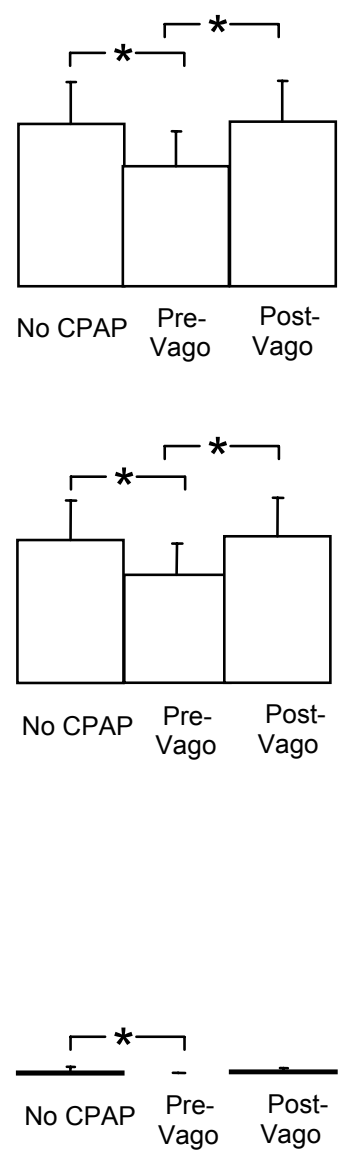

Isolated upper airway
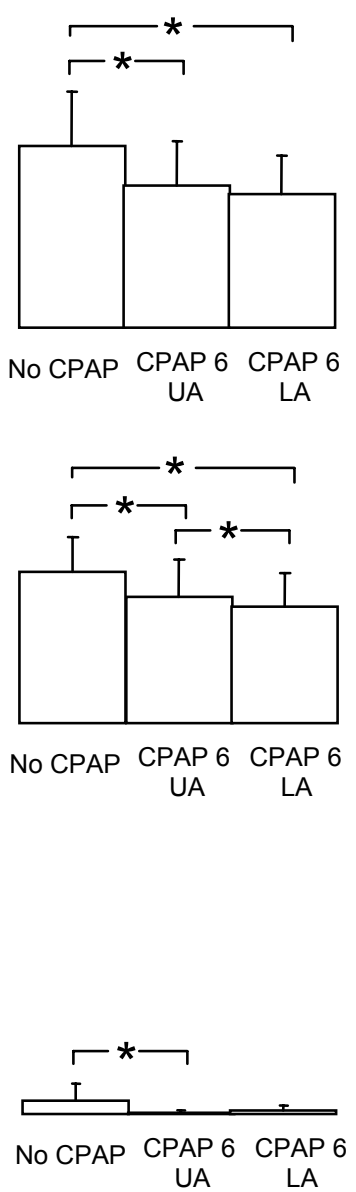
Figure 3:

Effect of continuous positive airway pressure on NNS-breathing coordination

\section{Tracheotomized group}
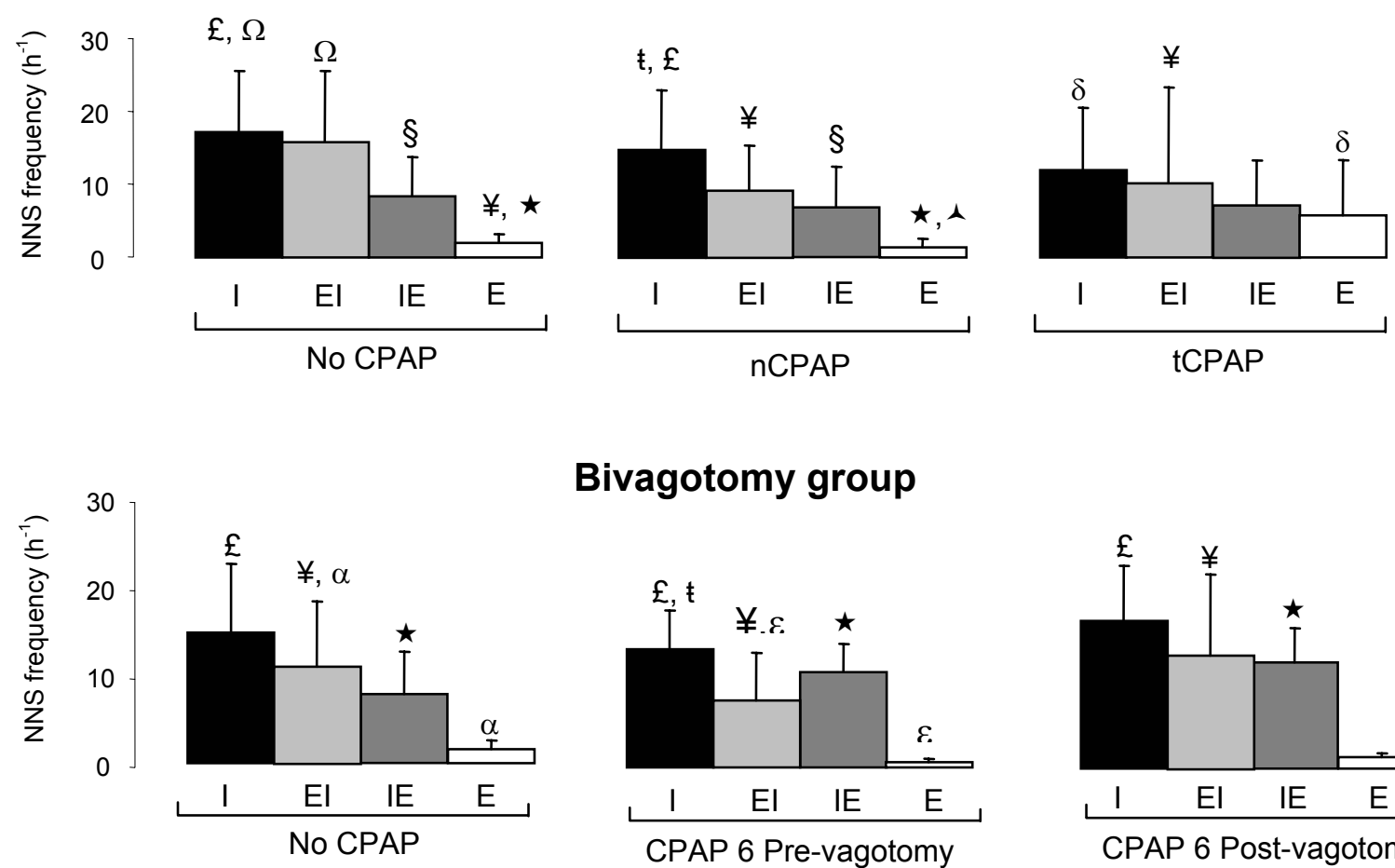

\section{Bivagotomy group}
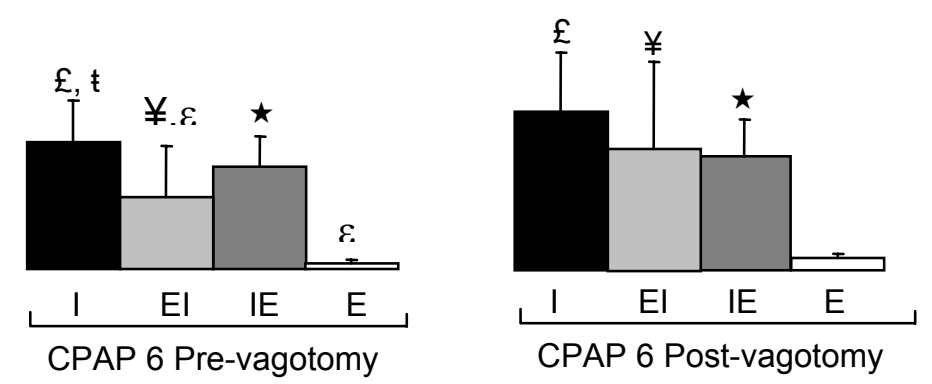

Isolated upper airway group
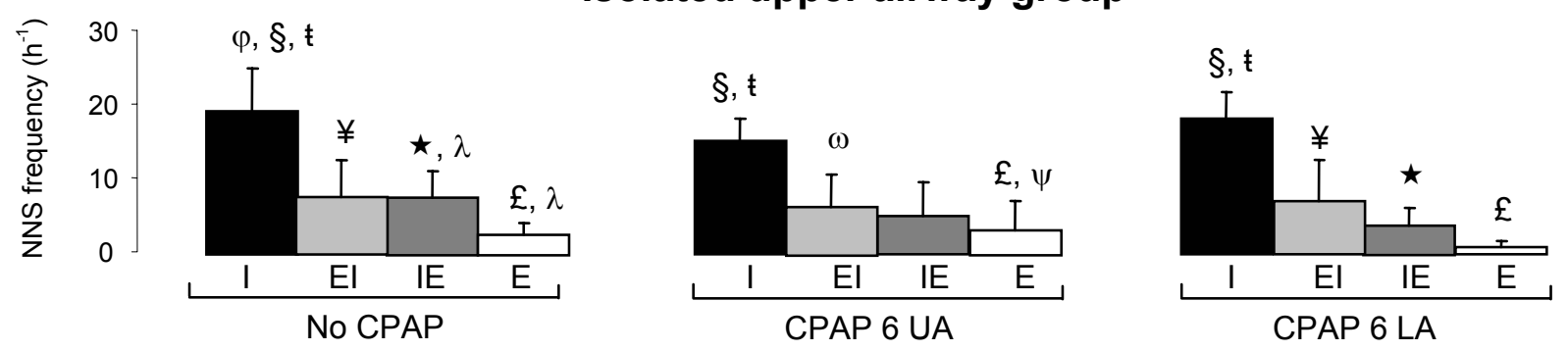


\section{Figure legends}

Figure 1:

Comparison of NNS frequency under no CPAP conditions for all three experimental groups (Bi-vago, bivagotomy group; Tracheo, tracheotomized group; Isol. UA, isolated upper airway group). Results obtained in a previous study (Samson et al, 2005) under identical experimental conditions, but in lambs with intact airways (intact airways) are added for comparison.

Figure 2:

Effects of continuous positive airway pressure (CPAP $6 \mathrm{cmH}_{2} \mathrm{O}$ ) on NNS frequency (number of NNS per hour) for all three groups (first column, tracheotomized group; second column, bivagotomy group; third column, isolated upper airway group) and for all different experimental conditions studied during quiet sleep: no CPAP, control breathing during which the lamb breathed through its nasal mask; $\mathrm{N}$, administration of a CPAP $6 \mathrm{cmH}_{2} \mathrm{O}$ through the nasal mask (nCPAP); T, administration of a CPAP 6 $\mathrm{CmH}_{2} \mathrm{O}$ through a cuffed tracheotomy tube (tCPAP 6), Pre-vago, administration of a nasal CPAP $6 \mathrm{cmH}_{2} \mathrm{O}$ before vagotomy; Post-vago, administration of a nasal CPAP 6 $\mathrm{cmH}_{2} \mathrm{O}$ after vagotomy, CPAP $6 \mathrm{UA}$, administration of a CPAP $6 \mathrm{cmH}_{2} \mathrm{O}$ on the upper airways only; CPAP 6 LA, administration of a CPAP $6 \mathrm{cmH}_{2} \mathrm{O}$ on the lower airways only. (A) results for total NNS frequency; (B) results for isolated NNS frequency; $(C)$ results for NNS burst frequency. * $P<0.05$. 


\section{Figure 3:}

Effects of continuous positive airway pressure (CPAP $\left.6 \mathrm{cmH}_{2} \mathrm{O}\right)$ on NNS-breathing coordination during the various experimental conditions. $i$-type, NNS preceded and followed by inspiration; ei-type, NNS at the transition from expiration to inspiration; ietype, NNS at the transition from inspiration to expiration and e-type, NNS preceded and followed by expiration. $\mathbf{P}<0.05$, i-type NNS vs. ei-type NNS; $§ \mathrm{P}<0.05$, i-type NNS vs. ie-type NNS; $£ \mathrm{P}<0.05$, i-type NNS vs. e-type NNS; $¥ \mathrm{P}<0.05$, ei-type NNS vs. e-type NNS; $\star \mathrm{P}<0.05$, ie-type NNS vs. e-type NNS; $\omega \mathrm{P}<0.05$, ie-type NNS vs. ei-type NNS; $\Omega \mathrm{P}<0.05$, no CPAP tracheotomized group vs. nCPAP $6 ; \delta$ no CPAP tracheotomized group vs. tCPAP 6; $\curlywedge \mathrm{P}<0.05$ nCPAP 6 vs. tCPAP $6 ; \alpha \mathrm{P}<$ 0.05 no CPAP bivagotomy group vs. CPAP 6 pre-vago; $\varepsilon \mathrm{P}<0.05$ pre-vago vs. postvago; $\varphi \mathrm{P}<0.05$ no CPAP isolated upper airway group vs. CPAP 6 UA; $\lambda \mathrm{P}<0.05$ no CPAP isolated upper airway group vs. CPAP 6 LA; $\psi$ P $<0.05$ CPAP 6 UA vs. CPAP 6 LA. 